\title{
In memoriam Prof. Paolo Biassoni (1929 - 2015)
}

\author{
Lorenzo Biassoni $^{1} \cdot$ Giuliano Mariani $^{2}$
}

Published online: 4 December 2015

(C) Springer-Verlag Berlin Heidelberg 2015

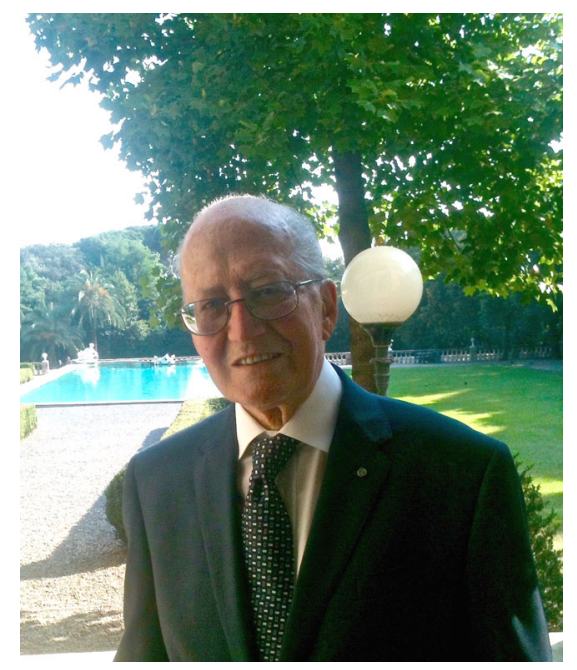

Professor Paolo Biassoni was a pioneer of Italian nuclear medicine. He was based at the University of Genoa, Italy, where he studied medicine and where he worked all his life. He and other colleagues were the backbone of the Radioisotopes Unit of the Department of Internal Medicine, which was opened in the early 1950s and which he joined in 1954, immediately after qualifying as a medical doctor. The unit was one of the first groups in Italy to use I-131 in the treatment of thyrotoxicosis. Biassoni did his MD thesis studying thyroid uptake of radioiodine in rats. Through this work, he developed a special

Lorenzo Biassoni

Lorenzo.Biassoni@gosh.nhs.uk

1 Great Ormond Street Hospital for Children NHS Foundation Trust, London, UK

2 University of Pisa Medical School, Pisa, Italy

interest for nuclear medicine, which was to stay with him for the rest of his life. Although nuclear medicine shaped his professional life, especially toward the end, he considered himself first of all a general physician, with a special interest in thyroid diseases, and inculcated in his students the critical importance of interpreting the nuclear medicine investigations in the global clinical context of the patient. He was appointed assistant general physician to the Department of Internal Medicine at the University Hospital of Genoa in 1964. In 1971 he was promoted to the position of deputy chief. In 1984 he became head of the Nuclear Medicine Unit of the University Hospital in Genoa. He worked in that capacity until 1995, when he retired from the National Health Service. In the mid-1980s he had been appointed a member of the Executive Committee of the former "Italian Society of Nuclear Biology and Medicine" (now "Italian Association of Nuclear Medicine"), where he served for a term, helping to steer the evolution of the society toward its current version in a time when the two components of nuclear medicine (nuclear physicians coming from general medicine versus physicians with a more prominent radiological background) were engaged in hot debate. Professor Giuliano Mariani, who was at the time the secretary of the association, is a witness to the balance and long-term vision that Biassoni showed in his interventions at the society's meetings. Years later, Mariani had another opportunity to interact closely with Biassoni when, in 1994, he moved to Genoa to work in the Nuclear Medicine Department of the University Hospital. The following year, after Biassoni's retirement, he replaced him as head of the Nuclear Medicine Department.

Biassoni also held a university appointment as Associate Professor of Nuclear Medicine and was director of the specialist training programme in nuclear medicine at the University of Genoa for some years. During his postgraduate training, he had obtained the title of specialist 
in haematology, radiology and nuclear medicine. He also passed the national exam to obtain the title of "Libero Docente" (a qualification that no longer exists in the Italian system) in internal medicine and nuclear medicine, enabling him to get involved in postgraduate teaching, which he passionately loved.

As a result of his many years of work in the Department of Internal Medicine and the Radioisotopes Unit, Biassoni became one of the Italian experts in the management of thyroid conditions. He and his coworkers set up a thyroid out-patient clinic in the University Hospital in Genoa, which became very well-known and attracted patients from all over Italy. He took pride in always fully examining every patient himself (not limiting himself to a clinical examination focused on only the specific condition to be treated), and by so doing he provided highly appreciated practical teaching to young undergraduates and postgraduates, who flocked to follow the ward rounds and the out-patient clinics that he led. He considered patients' care as his main duty as a physician and never hesitated to drop anything he was doing (even during holidays or free time) to look after a patient in need.

Biassoni was passionate about teaching and was very generous in devoting his energies to both undergraduate and postgraduate students. In return, he received countless demonstrations of gratitude from a very high number of his students across Italy. On many instances he was stopped, sometimes in the street, by former students of his, whom at that particular moment perhaps he might have even struggled to recognise, who wanted to thank him for having been taught something they considered very valuable.

Biassoni was born in Milan on 29th November 1929. He was the first of three children. His father, a chemical engineer, moved with his family to Genoa around the beginning of the Second World War. After having attended the Liceo Classico as a secondary school, he enrolled in the School of Medicine, which he completed with full marks in just less than six years - one of the first students of his year to qualify as a doctor. In 1958, he married Carla Parini, the daughter of a well-known maritime lawyer in Genoa. Their marriage was a very happy one, and five children were born. Their firstborn, Lorenzo, became a physician and is currently a specialist in nuclear medicine, thus continuing in his father's footsteps. Their second child died at 3 months of age. The third-born child graduated as an architect; a girl was then born, who is now an English teacher in secondary school, and the fifth child became a finance consultant. Biassoni travelled throughout Europe for nuclear medicine and endocrinology conferences, often bringing his wife and family, thus giving them an opportunity to enjoy this time with him. He had many cultural interests and was passionate about classical music, of which he had a very deep knowledge. He played the piano himself, having studied it for eight years in his youth with an excellent teacher. He loved nature and deeply enjoyed excursions in the mountains. Especially when he was young, but also as a mature man, he and a number of friends climbed several peaks and walked many footpaths of the Italian Alps. He was also a keen skier.

Biassoni was also passionate about using his expertise to improve the life of the unprivileged. A few years before retiring, he established an NGO whose aim was to provide healthcare and medical support to the populations of some areas of the Central African Republic and Peru. He directed this NGO for 25 years, drawing from this experience a great enthusiasm and drive that filled the 20 years of his retirement with passion and joy. Among his achievements were the creation of an iodine prophylaxis programme for populations of the Central African Republic, thus helping to prevent endemic goitre, and the building and opening of a centre to aid women about to give birth in the outskirts of Lima, Peru. He travelled to Africa and Latin America on several occasions, closely following the development of the various projects that he had set up. A rather shy and reserved person by nature, he became a very effective fundraiser and managed to secure the necessary funding to carry out these projects. His deep Christian faith was the root from which he drew energy and motivation for all his activities and which showed itself in a very kind and caring personality, in his self-giving to others in his family, work and social life, and his spirit of sacrifice in the fulfilment of his duties.

In April 2007, he fell from a ladder at home and sustained significant injuries. One of them, which eventually would lead to his death, was a haemorrhagic infarction of his myocardium (he was already on warfarin for atrial fibrillation). His left ventricular ejection fraction fell from a normal value to approximately $25 \%$, thus significantly limiting his daily activities. In September 2015, after two joyous summer months spent in the country house near Genoa, where he had been visited by many friends and relatives, he developed a pneumonia which eventually killed him after a few weeks in hospital. He died on 19th October 2015. His funeral mass was attended by more than 500 people; many others sent messages of condolences. Several colleagues of the Italian Society of Nuclear Medicine gave written witness to his caring personality, his great clinical knowledge placed at the service of whomever asked for his medical advice, and his self-giving to the unprivileged through his projects in Africa and Latin America.

He leaves Carla, his wife of 57 years, and their four living children, Lorenzo, Federico, Irene and Alberto. 